\title{
New ideas in the pathogenesis of nephritis
}

\author{
D GWYN WILLIAMS
}

From Guy's Hospital and Medical School, London SEI 9RT

Experimental work in the 1960's showed that in animals nephritis could be induced by two different methods-(i) reaction between antigen in the glomerular basement membrane (GBM) and antibody to it, the antibody arising either by immunisation of the host with autologous or heterologous GBM or by passive immunisation, and (ii) injection into the animal of foreign protein to cause acute (one injection) or chronic (repeated injections) immune complex disease. Thus models exemplifying antibody-mediated (type II) and immune complexmediated (type III) immune responses were established. Study of human nephritis showed that there are parallel disorders in the human kidney. Goodpasture's syndrome is characterised by a circulating antibody to GBM, transfer of which to primates reproduces the disease, and immunofluorescent study of the kidney shows the characteristic linear deposition of immunoglobulin and complement on the GBM. The evidence that immune complex disease occurs in man rests on appearances in the glomeruli similar to those in experimental animalsthat is, granular deposition of immunoglobulin and complement with the demonstration of an antibody to a defined antigen in the diseased glomeruli. The latter, more rigid criterion has been met in only a small number of instances.

The involvement of mediators such as complement, polymorphonuclear leucocytes, fibrin and platelets in producing glomerular damage initiated by either antibody alone or antigen-antibody complexes has been the subject of intensive investigation during the last fifteen years, both in experimental animals and in humans. Although not every mediator system is necessarily involved in each form of nephritis, both type II and type III mechanisms cause only slight or moderate tissue damage without the participation of mediators.

This article will briefly review recent additions to the knowledge outlined above and some of the current problems posed in trying to explain new data concerning nephritis. It will therefore not provide a comprehensive description of the pathogenesis of nephritis; this is outlined elsewhere. ${ }^{1-3}$

IMMUNITY OF THE HOST

The first experiments on chronic serum sickness in rabbits showed that some animals did not develop the illness, whereas others of the same strain were severely affected. This early signpost to the role of the host itself in the development of disease has led to a detailed description in various animal models of genetic susceptibility to nephritis, and correlates with observations in man of particular susceptibilities to disease associated either with deficiencies in the immune response or with particular tissue types.

\section{Human nephritis and the immune response}

A clear association of nephritis with deficiencies of the complement system, as well as with repeated infections and disorders of autoimmunity, has been recognised following the original reports in 1968 and 1971.4 Since the complement system plays a key role in the elimination of foreign antigens it is assumed that when it is defective the antigen persists and, as the antibody response is unimpaired in complement deficiency, antigen-antibody complexes continue to form, circulate, and become deposited in tissues.

Despite the numerous abnormalities of the immune system which can produce immune deficiency there are no other defects clearly recognised as being associated with nephritis, although we have recently noted in our unit a relation between IgA deficiency and systemic lupus erythematosus (SLE) presenting with nephritis. As knowledge of the complexity of the immune response grows it becomes more apparent that subtle defects may render the host immunodeficient and since certain types of immune deficiency are already treatable by appropriate replacement-for example, bone marrow transplantation, it is important to recognise these associations as they could lead to new treatments for nephritis.

\section{Association of HLA types and human nephritis}

Reports are accumulating of associations between various forms of human nephritis and particular HLA types (Table 1). The mechanism whereby an HLA type leads to the expression of a certain disease is not known, but the following are possible explanations: (i) the genes for the HLA type also directly influence the immune response; (ii) the HLA genes do not themselves directly influence the immune response, but they are closely linked to other genes, 
Table 1 HLA associations with glomerular diseases

\begin{tabular}{lll}
\hline Henoch-Schönlein purpura & BW35 & DRW1 \\
IgA nephropathy & BW35 & DRW4 \\
$\begin{array}{l}\text { Anti-GBM disease } \\
\text { Membranous nephropathy }\end{array}$ & & DRW2 \\
$\begin{array}{l}\text { Mesangiocapillary nephritis type II } \\
\text { Minimal change nephropathy }\end{array}$ & B12 & \\
SLE nephritis & B12 & DRW7 \\
\hline
\end{tabular}

as yet unidentified, which do; (iii) the HLA genes may code the cell surface receptors for antigens (such as viruses) responsible for the nephritis; (iv) the nephritis-inducing antigen may be so similar to the HLA antigen that the antibody response to the former is attenuated; this would lead to slow elimination of the antigen from the circulation and hence to persistence of circulating immune complexes.

FUNCTIONAL AND STRUCTURAL FACTORS IN THE KIDNEY PREDISPOSING TO NEPHRITIS It has long been appreciated that the large blood flow to the kidneys and their peculiar renal vascular anatomy contribute to their propensity to become diseased in the presence of circulating antigenantibody complexes. Other properties of the kidney are now considered to contribute to the development of nephritis.

\section{Complement receptors}

$\mathrm{C} 3 \mathrm{~b}$ receptor sites have been defined in the human kidney. ${ }^{5}$ Their existence is confined to primates. The sites are localised on the epithelial side of the basement membrane, and their apparent number is decreased in diseases associated with complement activation presumably because some of them are already blocked by $\mathrm{C} 3 \mathrm{~b}$. These sites probably contribute to the deposition of antigen-antibody complexes within the kidney by binding the $\mathrm{C} 3 \mathrm{~b}$ present on the surface of the complexes after they have activated complement.

\section{Antigen receptors and in situ formation of antigen- antibody complexes}

The interpretation of experimental and human data on nephritis caused by antigen-antibody complexes has been that the glomerular damage follows deposition of the complexes from the circulation. Recent evidence has, however, pointed to the deposition of antigen alone within the kidney with subsequent binding of antibody and hence formation in situ of an antigen-antibody complex. There would seem to be several mechanisms whereby an antigen may become fixed in the kidney.

(i) Mesangial uptake. When heat-aggregated human IgG was injected into rabbits it was localised in the mesangium. After transplantation of this kidney to a normal rabbit and administration of antibody against human IgG there was binding of the antibody to the antigen and hence in situ complex formation. ${ }^{6}$

(ii) Binding by charge. DNA, which is a highly charged anion, binds to the human GBM, and will combine with anti-DNA to form a complex.?

(iii) Reaction of antibody with antigens normally present in the glomeruli. This may be considered to occur in anti-GBM disease. It also occurs in an experimental setting known as passive Heymann nephritis, the name given to the disease which follows immunisation of rats with proximal tubular epithelial cells; the animals develop glomerular subepithelial immune deposits with histological and immunofluorescent appearances similar to those of human membranous nephropathy. Perfusion of rat kidneys with antibody against the antigen in tubular cells (known as Fx1 A) causes a similar appearance, leading to the conclusion that the rat glomeruli have antigens which can bind anti-Fx1A antibody to form complexes in situ. 89

These observations are among the most persuasive which have led to the notion that antigen-antibody complexes may form in situ in the glomerulus-a mechanism which is already known to operate in other organs-for example, the thyroid. In situ complex formation raises two important points. Firstly, it may explain the failure to detect circulating. complexes in certain forms of nephritis, and secondly it illustrates another possible mechanism whereby the host's own properties, in this case bindingcapacity, may influence the inception or course of the disease.

Lastly, although the idea of in situ complex formation is being put forward as a "new idea" in pathogenesis, it is worthwhile pointing out that this mode of antigen-antibody fixation in the kidney was the accepted dogma of sixty years ago. As is so often the case, the pendulum appears to have swung back.

\section{MEDIATORS OF INJURY}

\section{Antibody to renal basement membranes}

Further study of anti-GBM disease in man has shown that the antibody reacts with the non-collagen portion of the GBM. ${ }^{10}$ Some anti-GBM antibodies do not become fixed to the GBM of all human kidneys, thus indicating that not all human kidneys bear the same GBM antigens. The antibody crossreacts with the basement membrane of the pulmonary alveoli and of the choroid plexus, the former reaction explaining the pulmonary haemorrhage which is typical of Goodpasture's syndrome (although not all anti-GBM disease is accompanied by lung involve- 
ment). A clinical manifestation of the activity against the choroid plexus has not been recognised.

The development in man of anti-GBM antibodies is associated with exposure to hydrocarbons or penicillamine and with upper respiratory tract infections, although no particular organisms have been implicated. The underlying mechanism whereby the host produces autoantibodies against basement membrane is unknown but could be (i) by similarities between antigenic sites on the basement membrane and foreign antigens; (ii) alteration or exposure of antigens in the alveolar basement membrane by toxins or infecting organisms; (iii) loss of immune tolerance against basement membrane by reduction of the immunosuppressive mechanisms.

Antibodies against tubular basement membrane (TBM) have recently achieved some importance because of their demonstration in interstitial nephritis. They are found in association with the interstitial inflammatory changes occurring in anti-GBM disease, immune complex nephritis, drug-induced nephritis and rejection of grafted kidneys, in which they have also been found in the recipient's own kidneys. Anti-TBM antibodies are also found in idiopathic interstitial nephritis. Whether the anti-TBM antibodies are primary agents causing damage or arise secondarily after that damage remains a moot point as they are found in only a minority of the cases within each of the above groups, but particularly in those with the greatest degree of histological damage.

The occurrence of anti-TBM antibodies poses the question of the role of tubular antigens; this is discussed below.

\section{Complement}

Studies in human nephritis of serum concentrations of complement components and their breakdown products, of the rates of catabolism and synthesis of C4, C3, C5 and factor B, and of the demonstration by immunofluorescence of complement in nephritic kidneys have shown the contribution made by this mediator system to tissue damage. A recently recognised function of complement is the solubilisation of immune complexes. ${ }^{11}$ Decomplemented animals exhibited diminished clearance of glomerular antigen-antibody complexes in experimental nephritis. ${ }^{12}$ It is reasonable to assume that complement plays a similar role in man, and that the efficiency of the mechanism may be reduced in vivo by low plasma complement concentrations.

A profound abnormality of the complement system in human nephritis which has been much studied in the last few years is the identity of "nephritic factor" (NeF). This factor is found in some cases of mesangiocapillary glomerulonephritis
(MCGN) and is characterised functionally by its activation of complement via the alternative pathway, by which it contributes to the low plasma complement concentrations characteristic of this type of nephritis. NeF has now been identified as an IgG molecule, with a heavy chain of higher molecular weight than normal, ${ }^{13}$ whose antibody activity is directed against the $\mathrm{C} 3 \mathrm{bBb}$ moiety of the alternative pathway C3 convertase-that is, it is an autoantibody. ${ }^{1314}$ Its effect after binding is to prolong the half-life of the convertase by reducing its rate of degradation. ${ }^{15}$

The part played by $\mathrm{NeF}$ in MCGN remains unclear. It is not derived from the kidneys, since it persists after bilateral nephrectomy, nor is the outcome of the disease related to its presence or absence. It may predispose to the development of the disease by its reduction of plasma complement concentrations. A direct role by activating complement to produce glomerular damage has not been supported experimentally. ${ }^{16}$ Yet another possibility is that the occurrence of this unusual autoantibody is a marker of a genetic composition which predisposes by other means to the development of MCGN. Any explanation for the role of $\mathrm{NeF}$ must take account of its occurrence in partial lipodystrophy which is associated with and precedes nephritis, particularly MCGN, and is characterised by complement abnormalities identical with those of MCGN even in the absence of nephritis. ${ }^{17}$

\section{Cell-mediated immunity}

Reactions due to cell-mediated immunity (type IV) are notable in the field of nephritis for the absence of convincing proof that they contribute to the tissue damage. Circumstantial evidence that cell-mediated immunity is involved is provided by the presence of lymphocytes and macrophages in human and animal forms of nephritis, both as infiltrates in the interstitium and the mesangium, and, in the case of macrophages, as a constituent of crescents. Experiments have been conducted attempting to show transfer of disease by injecting syngeneic recipients with lymphocytes from diseased donors. Although the recipients have developed disease, the possibility has not been excluded that the inflammation was due to antibody generation or other alterations in the balance of immunological or inflammatory mechanisms caused by the donor lymphocytes without their direct participation in the renal damage. The role of macrophages in acute immune complex disease in animals has been emphasised by reduction of glomerular damage when the animals are treated with antimacrophage antiserum. ${ }^{18}$

A particular instance of human glomerular disease in which lymphocytes are thought to play an 
important role is "minimal change" nephropathy (MCN) which has long been an enigma owing to its remarkable response to steroids and immunosuppressive drugs, such as cyclophosphamide, despite the complete absence of any indication of inflammation or immune-mediated injury in the glomeruli. The abnormalities of lymphocyte function may be summarised as follows: (i) reduced transformation of nephrotic patients' lymphocytes by mitogens, which mostly returns to normal when remission occurs; ${ }^{19}$ (ii) inhibition by nephrotic patients' sera of the transformation of lymphocytes from normal subjects (although other reports suggest that this is not peculiar to $\mathrm{MCN}$ ):20-22 the inhibitor has not been identified, but it is not simply a lack of albumin or other essential substances; (iii) cytotoxicity of patients' lymphocytes to human kidney tissue in vitro; ${ }^{23}$ (iv) alteration in suppressor cell activity whereby patients who do not relapse after cyclophosphamide treatment have a significant diminution in suppressor cell activity compared with both normals and patients who despite cyclophosphamide continue to relapse; 24 (v) the association of MCN with Hodgkin's disease, with its own well-recognised abnormalities of lymphocyte function, and remission of the nephrotic syndrome on treatment of the lymphoma with radiotherapy.

It is difficult to synthesise these observations into a coherent whole. If cell-mediated immunity is involved in the pathogenesis of $\mathrm{MCN}$ then the histological lesion is unique because of the lack of abnormalities and we are possibly observing a manifestation of a reaction which is taking place away from the glomeruli though these are affected by some humoral mechanism.

IDENTIFIED ANTIGENS IN NEPHRITIS

A large number of antigens have now been implicated in nephritis due to antigen-antibody complexes. A

Table 2 Antigens implicated in human antigen-antibody complex-mediated nephritis

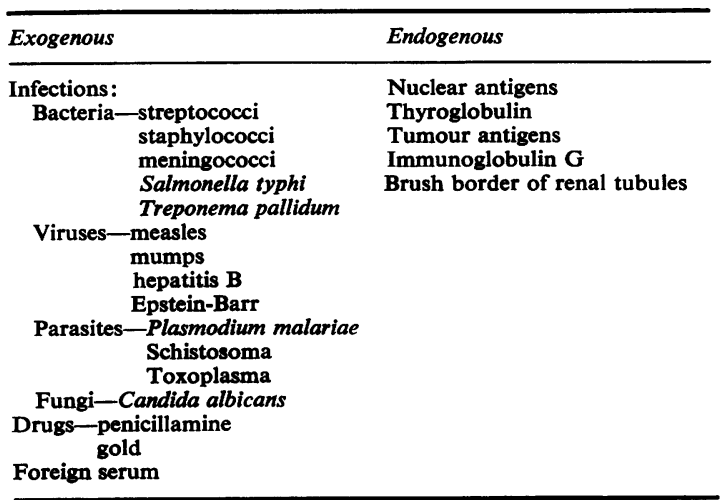

list, by no means comprehensive but illustrative of the range, is given in Table 2. Despite the number of antigens shown, it must be remembered that the number of patients in whom an antigen has been identified is small, and that the proof of identification ranges from association of the nephritis with a particular disease to elution of antigen-antibody complex from the glomeruli with identification of the constituent antigen and antibody.

Certain points are apparent from Table 2. Firstly, among the exogenous antigens the most numerous are infectious organisms. This is not surprising in itself, as they are by far the most plentiful source of foreign antigens we are likely to meet, but it raises the question of the factor(s) which lead to the development of nephritis in an individual, as there are many cases of infection caused by the same organisms which do not result in nephritis. This point of course leads us back to the notion that some attribute(s) of the host's immune response plays a crucial role in the development of nephritis.

Among the endogenous antigens the tubular antigens stand out as arising from the kidney itself. They are found in diverse condition such as sickle cell anaemia, renal cell carcinoma, the Fanconi syndrome and renal vein thrombosis but have not been detected in membranous nephropathy, histological equivalent in man of Heymann nephritis which arises in rats after the injection of tubulas antigens.

\section{Role of antigen-antibody complexes}

The frequency or usefulness, if any, of detecting $\stackrel{\triangleright}{\triangleright}$ antigen-antibody complexes in the circulation of $\overrightarrow{\vec{B}}$ patients with various forms of nephritis is dealt with 3 at length elsewhere in this issue (see Levinsky $R$, The role of circulating immune complexes in renal diseases). It is sufficient here to point out that the incidence of their detection in part depends on the ? test used, and that the complexes found in the circulation - that is, not deposited in tissues, may be telling us very little about the damaging complexes which are no longer circulating. Furthermore, the ubiquity of circulating complexes would seem to lessen their usefulness as a diagnostic aid, and it will $\frac{D}{O}$ probably be more relevant to our understanding of their significance to study their composition and $N$ their ability to generate inflammation.

One way in which the behaviour of immune complexes can alter disease is by the summation of $\omega$ their effect with that of circulating anti-GBM. ? Animals can be given either a dose of preformed $\stackrel{Q}{\llcorner}$

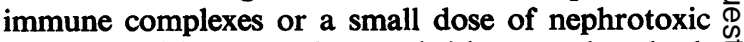
antibody without causing nephritis, yet when both are given together a severe nephritis ensues. ${ }^{25} \mathrm{~A}$ clinical counterpart of this is possibly seen in $\frac{O}{\mathbb{D}}$ 
anti-GBM disease which is stable but when an infection occurs an exacerbation of the nephritis may follow without a rise in anti-GBM titre in the serum. ${ }^{26}$

\section{Conclusion}

Work during the last five years on the pathogenesis of nephritis has shown that although type II and type III reactions play a major part in causing nephritis, they are not exclusively involved, and the contribution of the host through his/her own genetic control of the immune response and through various properties of the kidneys themselves are as important as the original insult. Improvement in treatment for nephritis may result from means of modifying the immune response to the advantage of the host rather than simply damping down the inflammatory process.

\section{References}

1 Cameron JS, Williams DG. Glomerulonephritis. In: Holborrow EJ, Reeves WG, eds. Immunology in medicine. New York: Academic Press, Grune and Stratton, 1977.

2 Albini B, Brentjens JR, Andres GA. The immunopathology of the kidney. London: Edward Arnold. 1979.

${ }^{3}$ Wilson $\mathrm{CB}$, Brewer $\mathrm{BM}$, Stein $\mathrm{JH}$, eds. Immunologic mechanisms of renal disease. Edinburgh: Churchill Livingstone, 1979.

4 Agnello V. Complement deficiency states. Medicine 1978; 57:1-23.

5 Gelfand MC, Frank MM, Green I. A receptor for the third component of complement in the human renal glomerulus. J Exp Med 1975;142:1029-34.

- Mauer SM, Sutherland DER, Howard RJ, Fish AJ, Najarian JS, Michael AF. The glomerular mesangium: III. Acute immune mesangial injury: a new model of glomerulonephritis. J Exp Med 1973;137:553-70.

${ }^{7}$ Izui S, Lambert PH, Miescher PA. In vitro demonstration of a particular affinity of glomerular basement membrane and collagen for DNA. J Exp Med 1976;144:428-43.

8 Barabas AZ, Lannigan R. Induction of an autologous immune complex glomerulonephritis in the rat by intravenous injection of heterologous antirat kidney tubular antibody. Br J Exp Pathol 1974;55:47-55.

9 Couser WG, Steinmuller DR, Stilmant MM, Salant DJ, Lowenstein LM. Experimental glomerulonephritis in the isolated perfused rat kidney. J Clin Invest 1978;62: 1275-87.

${ }^{10}$ Marquardt $\mathrm{H}$, Wilson $\mathrm{CB}$, Dixon FJ. Isolation and immunological characterisation of human glomerular basement membrane. Kidney Int 1973;3:57-62.

${ }^{11}$ Czop J, Nussenzweig V. Studies on the mechanism of solubilization of immune precipitates by serum. $J$ Exp Med 1976;143:615-30.

12 Bartolotti SR, Peters DK. Delayed removal of renalbound antigen in decomplemented rabbits with acute serum sickness. Clin Exp Immunol 1978;32:199-206.

${ }^{13}$ Scott DM, Amos N, Sissons JGP, Lachmann PJ, Peters DK. The immunoglobulin nature of nephritic factor (NeF). Clin Exp Immunol 1978;32:12-24.

14 Williams DG, Bartlett A, Duffus P. Identification of nephritic factor as an immunoglobulin. Clin Exp Immunol 1978;33:425-29.

15 Daha MR, Fearon DT, Austen KF. C3 nephritic factor (C3NeF): stabilisation of fluid phase and cell-bound alternative pathway convertase. J Immunol 1976;116: $1-9$.

${ }^{16}$ Verroust PJ, Wilson CB, Dixon FJ. Lack of nephritogenicity of systemic activation of the alternate complement pathway. Kidney Int 1974;6:157-69.

17 Sissons JGP, West RJ, Fallows J, Williams DG, Boucher BJ, Amos N, Peters DK. The complement abnormalities of lipodystrophy. N Engl J Med 1976;294:461-5.

18 Holdsworth SR, Neale TJ, Wilson CB. Abrogation of immune glomerulonephritis in rabbits by anti-macrophage serum. American Society of Nephrology Abstracts $1980 ; 86$ A.

${ }^{19}$ Schulte-Wissermann H, Lemmel EM, Reitz M, Beck J, Straub E. Nephrotic syndrome of childbood and disorder of T cell function. Eur J Pediatr 1977;124:121-7.

${ }^{20}$ Moorthy AV, Zimmerman SW, Burkholder PM. Inhibition of lymphocyte blastogenesis by plasma of patients with minimal change nephrotic syndrome. Lancet 1976;1: 1160-2.

${ }^{21}$ Iitaka K, West CD. A serum inhibitor of blastogenesis in idiopathic nephrotic syndrome transferred by lymphocytes. Clin Immunol Immunopathol 1979;12:62-71.

${ }^{22}$ Taube D, Chapman S, Brown Z, Williams DG. Depression of normal lymphocyte transformation by sera of patients with minimal change nephropathy and other forms of nephritic syndrome. Clin Nephrol 1981 ;15:28690.

${ }^{23}$ Eyres K, Mallick NP, Taylor G. Evidence for cell-mediated immunity to renal antigens in minimal change nephrotic syndrome. Lancet 1976; i:1158-9.

24 Taube D, Brown Z, Williams DG. Long-term impairment of suppressor-cell function by cyclophosphamide in minimal change nephropathy and its association with therapeutic response. Lancet $1981 ; \mathrm{i}: 235-8$.

${ }^{25}$ Trevillian P, Cameron JS. The interaction of antiglomerular basement membrane antibody deposition with immune elimination of bovine serum albumin in the rabbit. Clin Exp Immunol $1979 ; 35$ :338-49.

${ }^{26}$ Rees AJ, Lockwood CM, Peters DK. Enhanced allergic tissue injury in Goodpasture's syndrome by intercurrent bacterial infection. Br Med J 1977 :ii:723-5.

Requests for reprints to: Dr D Gwyn Williams, Renal Unit, Guy's Hospital and Medical School, London SE1 9RT, England. 